\title{
sciendo Methodology of conformity assessment with the essential requirements for electrotechnical products
}

doi:10.2478/mape-2019-0026

Date of submission to the Editor: 04/2018

Date of acceptance by the Editor: 07/2018

MAPE 2019, volume 2, issue 1, pp. 265-273

Tomasz Małysa*

ORCID ID: 0000-0002-9352-0528

Silesian University of Technology, Poland

\section{INTRODUCTION}

Ensuring the safety of products introduced in the European Union's single market is the primary responsibility of the introducer (producer, distributor, importer). Each entity that intends to introduce the product should ensure that its use does not pose a threat to the life and health of the user. Legal provisions defined by EU bodies and national regulations set out a number of requirements to be met if the product is covered by these regulations. The EU legislator defines safety requirements in the regulations and New Approach Directives. EU regulations are direct legal acts and do not require the transfer of their content in the form of a legal act issued by a national authority. In the case of directives, the national legislator is required to issue a legal act that will ensure effective implementation of the requirements of the directive. In the case of the analyzed issues, effective implementation of legal requirements takes place through a law or ordinance of a competent minister responsible for legal regulations in a given area.

The aim of the study is to present the problem related to the compliance of legal requirements by producers of electrical and electrotechnical branch products. An excessive amount of legal provisions results in situations in which manufacturers do not meet the legal requirements set by the new approach directives. In connection with the above, the methodology of the approach to the assessment of the product's compliance with the essential requirements has been developed. The usage this methodology in industrial conditions can facilitate the implementation of tasks related to ensuring security and correct performance of the conformity assessment process.

\section{SAFETY AND ASSESSMENT OF CONFORMITY OF PRODUCTS IN THE EU}

Every single day people buy various products which should be safe for the consumer in accordance with applicable regulations. For the products that separate regulations do not specify safety requirements, the act on general product safety in Poland is applied (Act of December 12, 2003), the provisions of which constitute the implementation of the provisions of the directive 2001/95/EC (Act of December 3, 2001). According to this document, every product placed on the market should be safe for the consumer and the entity introducing it should undertake all possible actions to ensure its safety. For products subject to the essential requirements, a separate approach to ensuring safety is provided.

\footnotetext{
* tomasz.malysa@polsı.pl
} 
Since the accession to the structures of the European Union by a given country, its industrial products are subject to the conformity assessment. The conformity assessment is understood as the compliance with the requirements of the EU legal acts by the product, particularly in the field of usage safety. The EU conformity assessment system is based on two documents, where apart from the principles of the new approach to the technical harmonization and standardization, an important element in the elimination of trade barriers was the determination of the criteria for a credible conformity assessment (Hamrol, 2013, Zymonik et al., 2013). The basic guidelines in this area were defined by the global approach to the research and certification resolution of the council of December 21, 1989. The basic goal of the global approach was to obtain a credible, transparent and reliable conformity assessment that would allow the creation of a system for the research recognition by the laboratories in EU countries. The assessment of the compliance with the so-called "new approach" is the fundamental obligation of the entity that introduces the product in the Single Market area. In Polish law, this obligation results from the Act on conformity assessment systems and market surveillance (Act of April 13, 2016). The legislator determined in the Act that the appropriate minister, by means of the conformity assessment subject, will determine by the regulation, the requirements for products being subject to the conformity assessment described in the new approach directives. The national regulations transposing EU Directives relate to the issues: the conformity assessment process, the scope of technical documentation for the product, the way of marking the product, the declaration of conformity.

The products placed on the European market should comply with the applicable Community legislation. Given that the manufacturer has detailed knowledge about the design and production process, he is the most competent to carry out the complete conformity assessment procedure. Therefore, the conformity assessment is one of the responsibilities of the manufacturer. The conformity assessment procedures are set out in Annex 2 of Decision No. 768/2008/EC of the European Parliament and the Council (Decision, 2008). The choice of the procedure is determined by the new approach directives for a specific group of products. There are eight main procedures (modules) for conformity assessment covering two phases - design and manufacturing. The conformity assessment may be based on (Hamrol, 2013):

- internal design and production control by the manufacturer,

- CE - type examination by a third party in combination with the manufacturer's internal production control,

- CE - type or design examination by a third party in conjunction with the approval of the product or production quality assurance system or product verification by a third party,

- design and production verification by a third party,

- approval of a full quality assurance system by a third party.

Once the conformity assessment process is carried out with a positive result, the manufacturer should issue a declaration of conformity and place the CE marking on the product in accordance with the requirements of the directives related to the product being the subject. As a part of the work carried out in the conformity assessment process, the manufacturer prepares proper documentation, performs the analysis and assessment of the risk. The legal regulations specify what should be included in the technical documentation, manuals and the declaration of conformity. Nevertheless, 
there is no information on the approach to the risk assessment associated with the product while in use. The choice of the risk assessment method is not simple, since there are many methods available to assess the risks associated with the usage of the products. The chosen method should comply with applicable directives, should be simple and understandable for the assessors and at the same time allow for a reliable risk assessment. In industrial practice, the indicator methods are the most popular - the risk is estimated as the product or the sum of the parameters characterizing the risk (i.e. the probability and severity of the consequences) (Małysa et al., 2016). The choice of the method will therefore depend on individual risk assessment preferences.

Compliance with the basic requirements set by the legislator does not guarantee the high quality of the product expected by the buyers. Therefore the manufacturers should undertake all steps aimed at meeting the quality expectations of the users of the products. These actions should be implemented at the product manufacturing stage at last, so that the existing problems do not affect the quality of the final product. The activities undertaken by the producers related to the proper organization and control of the production process will result in an increase of the quality of the final product. The actions taken in such way will result in cost reduction, and at the same time, in satisfaction of the customer (Gajdzik, 2013, Grabowska, 2018, Skuza et al., 2011).

\section{METHODOLOGY OF TESTS AND ANALYSIS}

The compliance of the electric and electrotechnical industry products with essential requirements is the fundamental responsibility of every entity introducing such products into the single European market. Thus, in order to ensure the repeatability of the performed tasks, a methodology of conduct was developed, allowing the implementation of steps in the area of meeting the essential requirements. The developed methodology (Fig. 1) distinguishes the following steps related to:

- identification of the product and its components - specification of the product, its purpose. At this stage the technical drawings, diagrams of components, subassemblies with their descriptions and explanations should be prepared for verification,

- assessment of the technical documentation - the manufacturer prepares the technical documentation of the product which makes it possible to assess the compliance with the applicable requirements and includes risk analysis and assessment. At this stage, it is necessary to check the completeness of the technical documentation developed and the risk assessment carried out,

- compilation of New Approach Directives related to the product - at this stage, New Approach Directives should be observed with regard to the designed and manufactured product. For the products placed on a single European market, the product may be subject to the requirements of not a single, but several new approach directives,

- compilation a list of harmonized standards for the product - at this stage all harmonized standards that apply to the product should be collated. A list of norms harmonized with the directives may be helpful in this respect. The harmonized standards compiled and used appropriately allow to meet the essential requirements and thus to the manufacturer's use of the presumption of conformity, referred to in the Act on conformity assessment systems and market surveillance, 
- design and manufacturing of the product in accordance with safety requirements - at this stage, the manufacturer should ensure that the designed product meet the requirements of harmonized standards and take all necessary measures to ensure that the production process and its monitoring ensure compliance of the equipment with the technical documentation,

- testing the finished product - the manufacturer examines the finished product in accordance with the requirements of the harmonized standards. The tests can be carried out by the manufacturer himself or by a third party independent laboratory,

- Declaration of Conformity and CE marking - the manufacturer after making sure that his product meets the essential requirements places CE marking on each product and draws up a written EU declaration of conformity for the product model and stores it together with the technical documentation at the disposal of national supervisors for a period of 10 years,

- placing the product on the market (final inspection) - a product that meets the essential requirements of all directives that apply to it can be placed on the market (the so-called multi-departmental products).

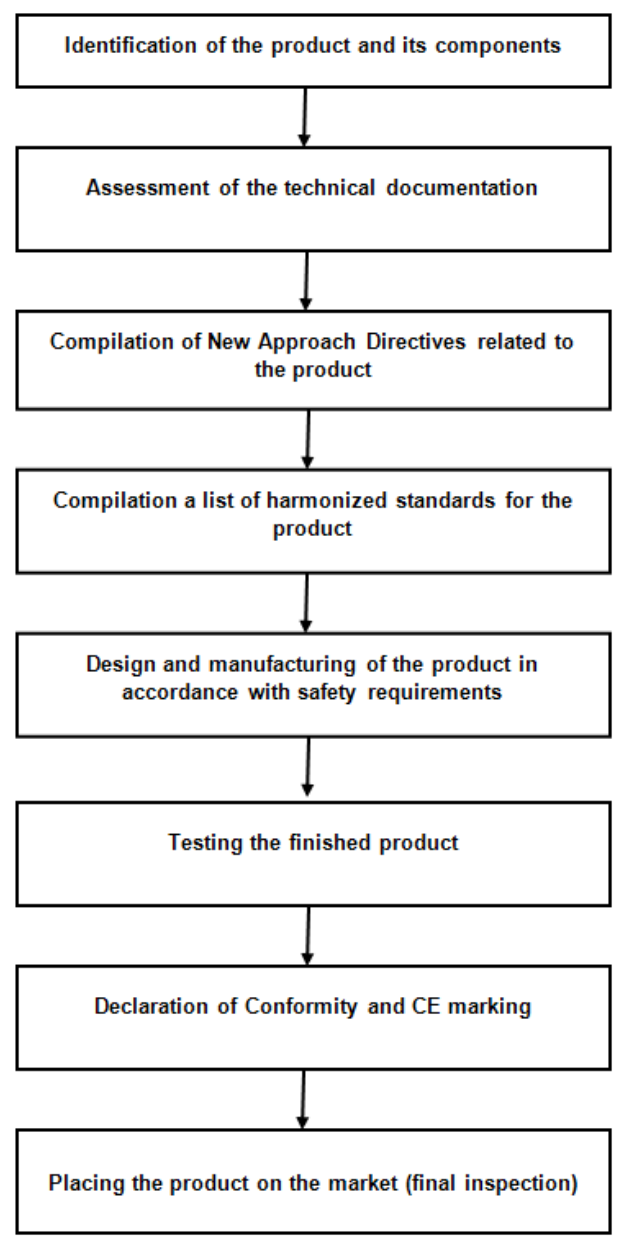

Fig. 1 Methodology of activities as part of meeting essential requirements for electrical and electrotechnical products

The methodology developed refers to the cases in which the manufacturer introducing the product fully applies the harmonized standards for the product. For the products for which there are no harmonized standards, the manufacturer may apply technical 
specifications. Then the product tests can be carried out by the manufacturer himself, notified body based on the technical specification he developed.

\section{ADAPTATION OF METHODOLOGY - PRACTICAL APPLICATION}

Ensuring the safety of products that are introduced into the single European market is an important and current topic for numerous manufacturing companies. The quality of products which consumers pay attention to is also becoming important. The study presents the application of the developed methodology in relation to a solid fixture with an LED module. At the first stage of the developed methodology (Fig. 1) the product identification was carried out and the documentation being the subject of conformity assessment was compiled. The completeness of the submitted documents, information contained in them allowed for the implementation of the second stage - the evaluation of the technical documentation of the product. In accordance with the requirements of the legal provisions, the manufacturer prepares the technical documentation enabling the assessment of the product conformity. Each documentation should contain information on the description of the general equipment, conceptual design, technical drawings, diagrams, descriptions necessary for their clarification and understanding and the results of the calculations. As part of the assessment and completeness of the information compilation, a list of control questions was prepared for which compliance was confirmed - table 1 . The second stage also included the analysis of test reports provided by the manufacturers of subassemblies making up the finished product. $A$ positive result was also recorded in this area. The third stage refers to the list of new approach directives that apply to the product in question. The lighting fixture is therefore subject to the requirements of (Directive of February 26, 2014, Directive of February 26, 2014, Directive of 8 June, 2011, Directive of 31 March, 2015, Regulation of 4 July, 2017):

- Directive LVD 2014/35/EU - electrical product, power supply 220-240V,

- Directive EMC 2014/30/UE - the lighting fixture contains electronically active elements (power supply for the lighting fixture containing active elements),

- Directive on the restriction of the use of certain hazardous substances in electrical and electronic equipment 2011/65/EU_and a delegated directive of the EU Commission - the product may contain substances subject to limitation, due to the integrated circuits used - the power supply,

- Regulation establishing the energy labeling framework (2017/1369) - the need to develop an energy label and make it available to the customer.

The new approach directives listed have their equivalents in the form of national regulations. This is due to the fact that directives require effective implementation into national legislation. The implementation of the above mentioned directives into Polish legislation took place in the regulations of relevant ministers due to the subject of conformity assessment. The requirements set out by the EU legislator in the form of directives were taken into account for the needs of the study. For the products for which harmonized standards cannot be used, technical specifications may be applied.

For the legal acts which the product is subject to, the harmonized standards have been compiled (Table 1). The selection of the harmonized standards that apply to the product in question was the fourth stage of the developed methodology. When introducing a product to the market, the manufacturer must confirm compliance with the standards by conducting appropriate tests. 
Table 1

Assessment of product conformity based on the developed methodology Adaptation of the methodology in practice

\begin{tabular}{|ll|}
\hline Product name: & Fixed luminaire with LED \\
\hline Application: & Industrial halls \\
\hline & Stage 2 - assessment of the technical documentation \\
\hline
\end{tabular}

Does the technical documentation contain:

- a general description of electrical equipment,

- conceptual design and technical drawings as well as diagrams of components,

subassemblies, circuits, etc,

- descriptions and explanations necessary to understand these drawings and schemes

and the operation of electrical equipment,

- results of design calculations, research and analyzes.

\begin{tabular}{l|l}
\hline Stage 3 - compilation & Directive 2014/35/EU (LVD)
\end{tabular}

of New Approach Directives related Directive 2014/30/EU (EMC)

to the product: $\quad$ Directive 2011/65/EU (RoHS)

Regulation 2017/1369

Stage 4 - compilation

a list of harmonized standards

PN - EN 60598-1:2015-04/A1:2018-04

for the product

PN - IEC 598-2-1:1994/Ap1:2000

PN - EN 62471:2010

PN - EN 55015:2013-10/A1:2015-08

PN - EN 61547:2009

PN - EN 61000-3-2:2019-04

PN - EN 61000-3-3:2013-10

Stage 5 - design and manufacturing of the product in accordance with safety requirements

Designing in accordance with the requirements of technical documentation.

Manufacture according to the assumed design.

Supervision of measuring equipment.

Monitoring of measuring equipment.

Qualifications and competences of the staff.

Stage 6 - testing the finished product

\begin{tabular}{ll|l|l}
\hline Testing of the finished product for compliance with standards in the scope of directives / Yes & No
\end{tabular}

Preparation of documentation

Directive 2014/35/EU

1) PN-EN 60598-1:2015-04/A1:2018-04 - Test report No.

2) PN-IEC 598-2-1:1994/Ap1:2000 - Test report No.

3) PN-EN 62471:2010 - Test report No.

Directive 2014/30/EU

1) PN-EN 55015:2013-10/A1:2015-08 - Test report No.

2) PN-EN 61547:2009 - Test report No.

3) PN-EN 61000-3-2:2019-04 - Test report No.

4) PN-EN 61000-3-3:2013-10 - Test report No.

\begin{tabular}{|c|c|c|}
\hline & Yes & No \\
\hline $\mathrm{x}$ & \\
\hline $\mathrm{x}$ & \\
& $\mathrm{x}$ & \\
& $\mathrm{x}$ & \\
\hline
\end{tabular}

\section{Directive 2011/65/UE (2015/863)}

\section{Certificate of conformity No.}

Stage 7 - Declaration of Conformity and CE marking

The declaration of conformity shall contain:

- product model (product number, type, series, batch),

- name and address of the producer,

- declaration concerning exclusive liability for the product,

- reference to New Approach Directives,

- reference to harmonized standards,

- date, place of issue, name and surname along with the signature of the person

authorized to issue the declaration of conformity,

Has the product been permanently marked - CE marking, and the marking applied meets $\mathrm{x}$

the formal requirements?

Stage 8 - placing the product on the market (final inspection)

The verified product fully meets the labeling requirements.

The verified product includes a declaration of conformity and CE marking.

\begin{tabular}{|c|c|c|}
\hline Yes & No \\
\hline$x$ & \\
\hline$x$ & \\
\hline$x$ & \\
\hline$x$ & \\
\hline$x$ & \\
\hline
\end{tabular}


Due to the conformity assessment process carried out (module A - internal production control), the manufacturer can carry out the tests on his own. Most often, however, manufacturers choose accredited laboratories and carry out tests for compliance with the standard. Often, the compliance with the standard is confirmed by a certificate of compliance under the New Approach directive.

The manufacturer should implement measures ensuring that the production process and its monitoring ensures the compliance of the manufactured product with the technical documentation. The activities undertaken in this area constitute the fifth stage of the methodology. At this stage, the manufacturer should implement activities that ensure high quality of the manufactured product and at the same time meeting legal requirements. He can also use the help of a third party that will assess the technical and organizational standards in the company. Within this area, design and production are analyzed in accordance with the technical documentation, supervision of measurement equipment, monitoring of measuring equipment aimed at ensuring its functional properties or assessment of personnel competence. As a part of the analysis, the compliance was recorded.

The testing of the finished product is the sixth stage of the adopted methodology. For the analyzed lighting fixture, the manufacturer conducted the tests for compliance with all identified standards, which was confirmed by the appropriate test reports. The report should refer to compliance with a given standard, not the points selected by the manufacturer. For the analyzed case, the manufacturer carried out tests and has relevant reports on compliance with the current harmonized standards, which are summarized in Table 1. As a part of this stage, the product manufacturer also used the certificate of conformity in the scope of RoHS Directive - 2011/65/EU (Directive of 8 June, 2011) relating to the limitation of some dangerous substances in electrical and electronic equipment. Therefore, it can be presumed that the product meets the essential requirements within the scope of this legal act.

The seventh stage refers to the verification of the EU declaration of conformity and the monitoring of compliance with the CE marking directive placed on the product. The low voltage directive, as it is assessed from its point of view, defines the model of the declaration of conformity. The model of the declaration of conformity is specified in the fourth attachment. Based on the analysis of the declaration of conformity stage 7 , it is stated that the declaration fully meets the requirements of the EU legislator. In the next step, the correctness of the CE marking was evaluated - above all, its dimensions. Compliance has also been registered in this area.

The last, eight stage of the evaluation, in accordance with the developed methodology, is the final verification whether all stages have been fully implemented. At this stage, it is necessary to assess whether the product has technical documentation, declarations of conformity and CE marking. Due to frequent monitoring by market surveillance authorities, attention is paid to energy labeling. Such label has been attached to the product. In connection with the above, it can be concluded that the product meets the essential requirements of the new approach directives and can be introduced into the Unified European Union Market. 


\section{CONCLUSION}

Ensuring the safety of the products placed on the European market is a current issue due to the legal consequences that producers may bear. Failure to meet the essential requirements involves financial penalties. The amount of penalties was determined by the legislator, in the Act on conformity assessment systems and market surveillance.

One of the solutions allowing for supervision over the conformity assessment process is the development of a methodical approach. The paper presents a tool proposal, within which the manufacturer has the option of a step-by-step assessment of whether he has carried out specific tasks resulting from legal provisions. The approach to the product conformity assessment presented in the article has been divided into eight stages within which conformity of the prepared documentation with the requirements of the directive is assessed, new approach directives are identified, harmonized standards refer to the designed and manufactured product, the manufacturer supervises the production and examines the product. The final stages of the methodology are connected with the development of a declaration of conformity, which is a statement by the manufacturer that the product meets the requirements of the directives. Meeting all the stages within the developed methodology may be a confirmation that all activities resulting from legal provisions have been met.

In the study, the product was subjected to analysis - a lighting fixture. According to the adopted methodology, verification of the fulfillment of the essential requirements was carried out (Table 1). Basing on the analyzes carried out, it was found that the product introduced into the single market meets the requirements of directives that have been identified for it. The manufacturer carried out the tests that were confirmed by reports and supervises the work performed by employees during the production process and added appropriate documentation to the product.

\section{REFEENCES}

Act of 13 April 2016 on conformity assessment and market surveillance systems.

Act of December 12, 2003 on general product safety.

Commission Delegated Directive (EU) 2015/863 of 31 March 2015 amending Annex II to Directive 2011/65/EU of European Parliament and of the Council as regards the list of restricted substances.

Decision No 768/2008/EC of the European Parliament and of the Council of 9 July 2008 on a common framework for the marketing of products, and repealing Council Decision 93/465/EEC.

Directive 2014/35/EU of the European Parliament and of Council of 26 February 2014 on the harmonization of the laws of the Member States relating to the making available on the market of electrical equipment designed for use within certain voltage limits.

Directive 2014/30/EU of the European Parliament and of Council of 26 February 2014 on the harmonization of the laws of the Member States relating to electromagnetic compatibility.

Directive 2011/65/EU of the European Parliament and of Council of 8 June 2011 on the restriction of the use of certain hazardous substances in electrical and electronic equipment.

Directive 2001/95/EC of the European Parliament and of Council of 3 December 2001 on general product safety.

Gajdzik, B. (2013). World class manufacturing in metallurgical enterprise. Metalurgija, 52(1), pp.131-134.

Grabowska, S. (2018). Improvement of the heat treatment process in the Industry 4.0 context. In: METAL 2018: 27th International Conference on Metallurgy and Materials, pp. 19851990. 
Hamrol, A. (2013). Quality management. Warsaw: PWN.

Małysa, T., Nowacki, K., Furman, J. (2016). The risk management methodology in the metallurgical enterprises. In: METAL 2016: 25th International Conference on Metallurgy and Materials, pp. 1925-1930.

PN-EN 60597-1:2015-04/A1:2018-04 - Luminaries - Part 1: General requirements and test.

PN-EN 62471:2010 - Photobiological safety of lamps and lamp systems.

PN-EN 55015:2013-10/A1:2015-08 - Limits and methods of measurement of radio disturbance characteristics of electrical lighting and similar equipment PN-EN 61547:2009 Equipment for general lighting purposes - EMC immunity requirements.PN-EN 61000-3-2:2019-04 Electromagnetic compatibility (EMC) - Part 32: Limits - Limits for harmonic current emissions (equipment input current $<=16 \mathrm{~A}$ per phase.

PN-EN 61000-3-3:2013-10 Electromagnetic compatibility (EMC) - Part 3-3: Limits - Limitation of voltage changes, voltage fluctuations and flicker in public low-voltage supply systems, for equipment with rated current $<=16 \mathrm{~A}$ per phase and not subject to conditional connection.

PN-IEC 598-2-1:1994/Ap1:2000 Luminaires - Specific requirements - Fixed general purpose lighting fixtures.

Regulation 2017/1369 of the European Parliament and of the Council of 4 July 2017 setting a framework for energy labeling and repealing Directive 2010/30/EU.

Skuza, Z., Prusak, R., Budzik, R. (2011) Contemporary elements of quality management system in the metallurgical enterprises. Metalurgija, 50(2), pp. 137-140.

Zymonik, Z., Hamrol, A. and Grudowski, P. (2013). Quality and safety management. Warsaw: PWE.

Abstract. The article presents a methodical approach to conformity assessment related to the introduction, putting into service on the European market of electrical or electrotechnical products. The developed methodology can be an effective control tool, allowing to assess whether all activities within the conformity assessment performed by the manufacturer have been carried out. The aim of the study is to present the possibility of adapting the developed methodology of approach to the assessment of compliance with the essential requirements in industrial conditions. In the case of the industry being analyzed, the basis for conformity assessment is the requirements set out in the New Approach Directives. The essential requirements set out in New Approach Directives must be met if the product is placed on the market or putting into service. The article presents the implementation of the conformity assessment process based on harmonized standards with the directives related to the product in question. The application of harmonized standards in the conformity assessment process allowed the manufacturer to use the so-called principles of presumption of conformity, referred to in the Act on conformity assessment systems and market surveillance.

Keywords: conformity assessment methodology, essential requirements, electrotechnical products 